Portland State University

PDXScholar

\title{
Languaging as Competencing: Considering Language Learning as Enactment
}

John Hellermann

Portland State University

Follow this and additional works at: https://pdxscholar.library.pdx.edu/ling_fac Let us know how access to this document benefits you.

\section{Citation Details}

Hellermann, John, "Languaging as Competencing: Considering Language Learning as Enactment" (2018). Applied Linguistics Faculty Publications and Presentations. 30.

https://pdxscholar.library.pdx.edu/ling_fac/30

This Post-Print is brought to you for free and open access. It has been accepted for inclusion in Applied Linguistics Faculty Publications and Presentations by an authorized administrator of PDXScholar. Please contact us if we can make this document more accessible: pdxscholar@pdx.edu. 
Hellermann, J. (2018). Languaging as competencing: Considering language learning as

enactment. Classroom Discourse, 9(1), 40-56. Author's manuscript/post-print version

\section{Introduction}

This contribution to the special issue on interactional competence and its development for language learners considers the questions: what is language learning and how do we see it in longitudinal data sets using theory and methods from ethnomethodological conversation analysis (EMCA)? The questions arise from the different perspectives on language provided by structural linguistics and individual cognition on the one hand and the action-oriented, collaborative EMCA on the other. The legacy of structural linguistics in language learning research has been enriched by functional and interactional approaches and the construct of interactional competence (Hall 1995, Kramsch 1986, Young, 1999) has developed out of dissatisfaction with that legacy (see Hall, this volume, for a succinct overview of this development). However, the reliance on written forms for the description, analysis, and assessment of talk-in-interaction suggests further discussion of the nature and representation of language and learning as conceptualized in interactional competence is warranted.

In her review, Hall also suggests the need for new terminology due to the overlapping references of interactional competence: 1 ) the fundamental competence of all humans to interact and 2) the objects of learning. I will address two different aspects of the conceptualization of interactional competence. The first is the mechanism or process of change in a learner's communicative, interactional repertoire and to what degree we may gain from the use of new conceptions of cognition. The second, related to the first, is the issue of the ontology of structural linguistic representations as an individual's products of learning and the ways EMCA methods allow us to see different evidence of learning.

This contribution hopes to add to the detailed discussion of practice-based approaches to the conceptualization of learning by Koschmann (2011) and by bringing in theory from cognitive science and more distributed approaches to linguistics. The reason for the development of this argument arose after considering the case of a particular language learner ' $\mathrm{Li}$ ' (Hellermann 2017, Hellermann and Harris 2015). As the data excerpts will show, although the label interactional competence and a change in interactional competence fits the change in Li's participation, in order to fully describe that change, I want to reconsider some of the theoretical heritage that has come with conceptualizations of interactional competence. The theoretical heritage is linguistics' formal conceptualizations of language and its reliance on the study of written forms. This heritage is firmly rooted in (second) language acquisition research and for that reason continues to be an issue interactional researchers face in their analyses of talk-in-interaction and conceptualizations of learning

In order to set up the data excerpts, the paper first discusses EMCA's approach to investigating interactional competence and how that has been adopted by language learning researchers. The second section discusses the change aspect of learning and suggests a conceptualization of learning as enactment. The third section questions the degree to which we can use representations from structural linguistics to show evidence of learning. The two data excerpts follow which show $\mathrm{Li}$, a learner of English, performing the same classroom language learning task five months apart.

\section{Theories and methods of seeing changing competent interaction}

The goals of ethnomethodological conversation analysis (EMCA) are to uncover and display members' methods and competences for accomplishing situated social organization. The outcomes of the research, the product, what is seen as competence for members, is in their displays of understanding and the accountability they hold one another to for ordinary contextualized behavior. Knowing how to act in context (competence) and the use of accountable interactional resources for interacting in context cannot be separated in an EMCA approach. For EMCA, the competence of members is investigated in the context of interaction and members's orientations to one another in 
interaction. Competence in EMCA is, by definition, an interactional competence, the ability to engage in appropriate interactional practices in particular contexts.

For an EMCA researcher to investigate learning, the conceptualizations of learning must foreground the local, contextualized sense making practices and will, therefore, be "alternatives to ...connectionism and cognitive representationalism" (Koschmann 2011, p. 8). My sense is that other EMCA researchers interested in learning and/or interactional competence would conceptualize learning in this manner (Kasper 2009). My own work has arrived at conceptualization influenced by studies of interaction and culture (Cole 1996, Lave and Wenger 1991, Ochs 1988), educational linguistics (Hall 1993, Halliday 1993, van Lier 2004), and most importantly, EMCA (Macbeth 2011, Zemel and Koschmann 2014). Recently, the empirical studies of learning settings and the ethnographic longitudinal data collections that arose from studies of those settings has also been influential to research on interactional competence. Technological advances have made such long-term collections of video recorded interactions convenient and CA methods have been able to begin to uncover the micro-level unfolding of language learning in ways that had not occurred previously (Brouwer and Wagner 2004, Markee 2000, Wooton 1997). Although CA methods were developed in the 1960s, it was not until relatively recently that data collection has been done to enable close sequential analysis to provide evidence of processes of change. The data and research design helped answer Kasper's question (1997) about where CA might find acquisition. The data allowed participatory theories of learning to be illustrated empirically by examining interactional practices. The longitudinal nature of the investigations also made relevant conceptualizations of learning and competence that are not consilient with EMCA, culturally-dominant normative theories of learning from educational psychology (see Koschmann 2011 for a discussion ${ }^{1}$ ).

Although there are analytic benefits to tracing linguistic formulations over time, longitudinal data and large collections of linguistic products lead to at least two related questions (Hellermann 2011, Nguyen 2017, Pekarek Doehler 2010): 1) to what degree can observed change be attributed to the individual or to the context of the interaction?, 2) how is a relevant change observable with the contextdependent, local sense-making approach to understanding interaction in EMCA?. The now robust empirical studies show quite clearly that evidence of changes in language behavior can be traced using EMCA methods (Barraja-Rohan 2015, Eskildsen 2012, 2015, Fillipi 2015, Hellermann 2008, Markee 2008, Nguyen 2013, Wootton 1997). Yet the fact of tracing these items in the production of an individual suggests an individualist and structure-focused conceptualization of language and cognition remains in these EMCA-grounded studies. Questions that remain to be investigated are: how has participation changed and how was the participatory transformation co-constructed?

\section{Change via enactment}

Support for the EMCA position on publicly built intersubjectivity as the site of cognition and learning can be found in recent work in on consciousness, learning, and the mind in cognitive science (Gallagher and Allen 2016, Hutto and Myin 2013, Manzotti 2016, Thompson 2007, Varela et al. 1991). This particular line of cognitive science research draws heavily on phenomenology, (particularly Merleau-Ponty) a philosophy linked to the micro-level sociology that became EMCA (Heritage 1984). These cognitive scientists have looked to phenomenology to work out a bridge between the internal mind and external world, how it is that an individual cognizes a seemingly shared objective world. Demanding a monist (rather than metaphysical) explanation for experience and cognition and not finding one in neurology (Manzotti, 2016) ${ }^{2}$, phenomenologically-informed cognitive scientists have been exploring explanations of the self as a dynamic, unbounded, and shared entity. This is a continuing development of alternatives to Cartesian mind-body separation which has been conceptualized in

\footnotetext{
${ }^{1}$ See also Lynch and Wong (2016) and Lynch and Macbeth (2016) for recent critiques of generalization in EMCA as well as Everett (2016) for a similar critique in linguistics.

${ }^{2}$ Although the role of neuronal activity in cognition is not questioned, the patterned activity of neurons is not taken to be an adequate explanation for socio-culturally embedded, contextualized learning.
} 
phenomenology (Husserl 1980, Merleau-Ponty 1962) and linguistics (Becker 1984, Harris 2009) and which may be familiar to readers as distributed cognition (Cowley 2009, Hutchins 1995). In this alternative, there is no strict separation between an agentitive, intentional individual mind and the context around it. The world outside the self is, therefore, considered not simply as a source for mental representations and cognition via perception but is an interactant shaping apperception. From this perspective, one's identity, cognition, language, and language learning are not individual cognitive representations, but are part of the process of an unfolding history of interaction with the world. The consequence of this is that to explain talk-in-interaction and learning, we need not rely on intermediate mysterious internal symbolic representations of the world or internal representations of language as an intermediate step between perception, interaction, language, and learning.

In this holistic, unified view of language and action, cognition and learning is conceptualized as enactivism (Hutto and Myin, 2013, Manzotti 2016, Varela et al. 1991), that is, the dynamic interplay between mind, body, the environment, and action. The relationship between perception and action is mutually-reinforcing: "cognitive structures emerge from the recurrent sensorimotor patterns that enable action to be perceptually guided" (Varela et al. 1991, p. 173). This reflexive conceptualization of cognition examines it as experienced practice, as it happens, as a dynamic interactional process. This contrasts with psycholinguistic models such as the input-processing computational metaphor that relies on mental representations of linguistic forms has been influential in SLA research (Gass 2013). Enactivism aligns with various approaches to linguistics and language acquisition that do not foreground mental linguistic representations such as integrational (Harris 1981) and ecological (van Lier 2004) because it repositions cognition and the work of the brain/mind at the intersection of perception and somatic (including the brain) activity.

\section{The distraction of ready-made features: representation in cognition and linguistics}

This radically action-oriented view of cognition suggests that linguistic systems do not have the convenient psycho-physical correlates that linguists' graphically-focused studies lead us to believe (Linell 2005). The enactivist view of cognition and language help us see linguistic forms or linguistic systems as after-the-fact descriptions of language, not the lived experience of language itself. Enactivism can, therefore, lend support to EMCA research on language learning that has suggested linguists and language educators consider language, cognition, and learning as embedded in social action rather than consisting of abstract mental representations. In this respect, the 'language' of language learning is not a representation; not the object that appears in the student's grammar book. Rather, what is learned is the language user's enactment of an interactional/cognitive procedure made possible by that enactment (Varela et al. 1991). Put another way, talk-in-interaction is the routine of multiple parties producing a series of approximations in context sensitive ways (Hopper, 1988) as part of accomplishing some activity. The approximations used are determined and, perhaps, refined as they are used (Wertsch and Kazak 2011). The traditional metaphors for language learning ('competence', 'portable', 'individual') that may be vexing to EMCA approaches to language learning research result from the input-processing or telementational (Harris 1981) conceptualization of language. Such a conceptualization relies on an internal grammar or set of mental representations, constructs that are not yet defined (Gallagher 2017). In contrast, this 'competence' is explained from an enactivist approach as dispositions for appropriate contextualized language use resulting from accumulated experience involving, among other things, memory and automatized somatic patterns. Such representations can be recorded, repeated, and described as linguistic expressions in grammar books. But we need not consider them mapped as linguistic expressions in an actual mental grammar.

From the preceding discussion, I hope to have shown that an enactivist approach to language, learning and cognition has import for the way we discuss language as part of interactional competence. For researchers of interaction and language use and learning, an enactivist approach forces us to reconsider terminology and constructs we have inherited from a number of sources including structural linguistics and SLA. This reconsideration may help us move toward a more accurate understanding of 
learning which can be uncovered using EMCA analytic methods. This involves continuing to focus on action as EMCA methods stipulate but also considering how non-representational conceptualizations of cognition and linguistics suggest that products or objects of learning might be operationalized. The methods of EMCA well-positioned to uncover these non representational conceptualizations. EMCA does not start, as SLA approaches generally do, grounded in structural theories of linguistics that had as their starting point formal grammatical structures. EMCA focuses on identifying actions accomplished (repair, tellings, offers, etc) and the interactional practices used for those actions (Kasper 2006). At this stage, however, even though the analyst knows that particular actions can be accomplished using an almost infinite number of interactional practices, the reporting and dissemination of findings become reified by the reporting of the findings. As discussed in the recent debate of research on epistemics (Macbeth, Wong, and Lynch 2016), the reporting on the use of a particular linguistic formulation may be treated, because of its reification in written research reports, as having a similar interactional import in all contexts. Language practices that are reified as abstract linguistic structures and rendered in print may distract from EMCA's focus on actions and interactional practices to a focus on written linguistic forms.

Many studies of interactional competence among language learners have used emergent grammar (Hopper 1998) as a theoretical grounding for seeing processes of change in language behavior. However, a recent paper by Ford and Fox (2015) is a reminder that the emergence of a structure or pattern in interaction does not necessarily imply emergence of a stable, for-all-time structure. For research on learning, the implications for the lack of guarantee of permanence is to explain how learners' changing practices from the use of a particular expression to an expansion of that expression (Pekarek Doehler and Berger, 2016) is the development of an increasing repertoire of approximations, of practices, of action-practice gestalts.

\section{Data and Methods}

The data I work with are from institutionally-defined settings for learning and, therefore, the data themselves make certain questions and approaches to answering those questions more relevant. The contexts that I have chosen for data collection and analysis are contexts in which participants orient to (in most cases) being engaged in interaction for learning and the data were collected using a longitudinal design. So, because of the longitudinal nature of the data, the fact that participants orient to themselves as learners, to being in places for learning, and the fact that research teams I work with include practitioners who ask questions of the data that are fundamental to their professional practice, I ask of the data: are these people learning? If so, what are they learning and how?

I will present two data extracts to illustrate evidence for Li learning how to be a student in a language learning classroom and how language is learned in the context of learning a particular task. I use the extracts to make a case for considering learning as enactment and to show how focusing on language structures may not provide evidence for change. The excerpts come from the interaction of a beginning level learner of English ('Li') who participated in a community college English language class for two years. The two excerpts show $L i$ in a similar classroom task on two different occasions, 8 months apart, the first in October, the second in May. Data were recorded with six cameras and five microphones in the classroom (Reder 2005). Li was wearing a wireless lapel microphone. More detail on $\mathrm{Li}$ can be found in a case study in Hellermann and Harris (2015). The transcripts have followed Mondada's conventions for multimodal interaction (2014) and a sequential analysis according to principles of conversation analysis was undertaken. The excerpts selected are two instances of $\mathrm{Li}$ working on a similar language learning activity in a classroom. They illustrate the collaborative, contextualized performance and enactment of a language learning task and language learning as an epiphenomenon of participating in the task. Comparing the excerpts in (1) to those in (2), I argue stark differences in the process of resource use to accomplish each task are visible.

\section{Data excerpts}




\section{Excerpt set 1: Li's first month in the classroom}

Excerpts $1 \mathrm{a}$ and $1 \mathrm{~b}$ from October, illustrate how a number of semiotic resources are used collaboratively by $\mathrm{Li}$, her peer, and the classroom instructor to recognize a question-answer sequence as part of a classroom task and to accomplish that task. The participants are (figure 1 ) Li, sitting at the table to the left with the gold and black clothing, her classmate Shen, sitting next to her in red, and the instructor, Tess, on the right side of the screen capture, kneeling in front of the table. The italics in the transcript indicate an English-language translation of a Taiwanese dialect of Mandarin as you see in lines 7, 8, and elsewhere.

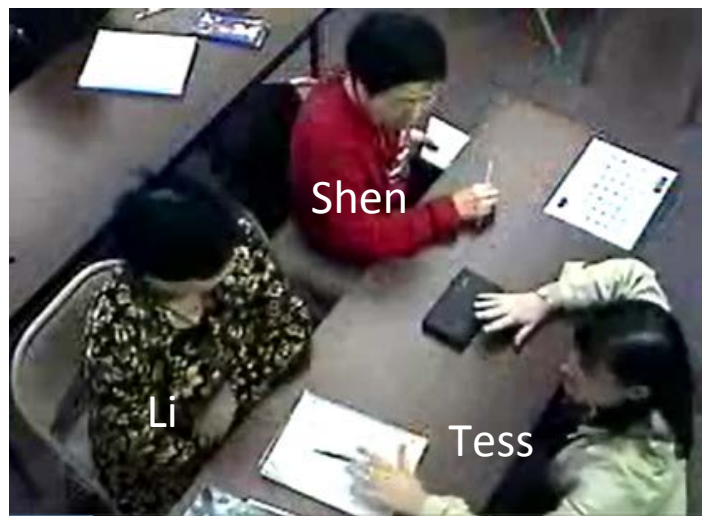

Figure 1 Participants in excerpts (1a) and (1b)

Just prior to (1a), Tess has given explicit instructions for $\mathrm{Li}$ and her peers to ask one another about their daily habits, including 'what time do you get up'. We see that by the end of excerpt (1b), using a number of interactional resources including gesture to objects, pantomime, a peer's indication of writing on the board, and a shared L1, Li answers the first question of the task. It is clear at the start that Li is oriented to by the Tess as a novice. While other students are working together without the help of Tess, Tess kneels in front of Li and Shen's desk and, rather than listening to the pair accomplish the task, she articulates the task prompt directing it via her gaze to Li. Lines 5 and 6 show the complex turn construction and recipient design work bracketing the turn with a discourse marker okay and then breaking it up into two parts, separating the focal element time from the verb phrase while making it salient by stretching the vowel. Her second TCU repeats the focal item without the question word and uses a gestural index (touching her own watch) to a recognizable tool for measuring time and a related question. The question is followed by Li who does not respond to Tess' question but makes a translation of it into Taiwanese including a formulation as reported speech about what Tess said. Although there is no immediate verbal uptake to that translation from Li, Shen, or Tess, at the end of Li's turn, Shen points to the board which Li orients to with her gaze shift.

(1a) [10-14-04, 2002, 204, 46:31-46:46]

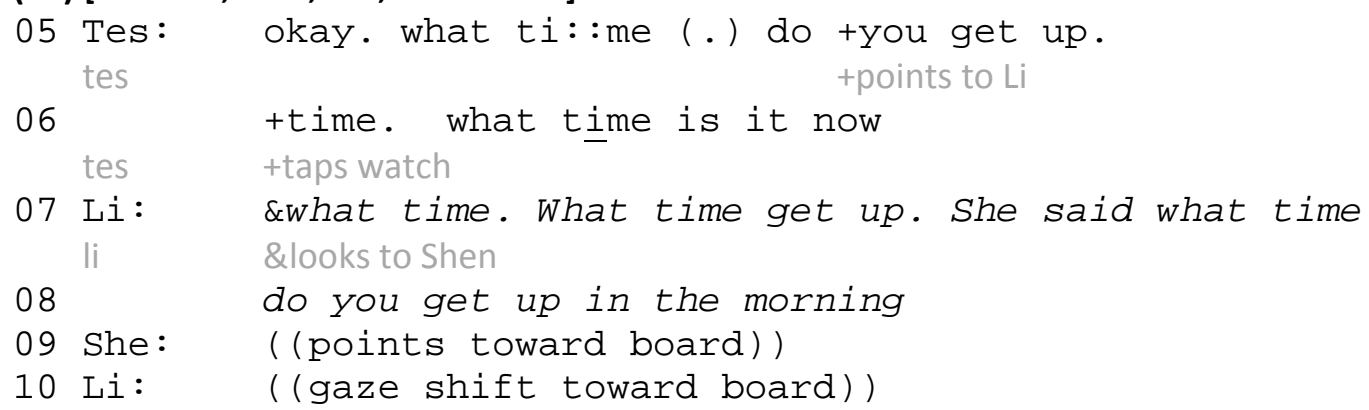

Excerpt (1b) continues immediately from (1a) and shows that upon gazing to the board, Shen reports on evidence found there to make sense of Tess' query. She makes public (in line 11) her observation of the 
letter $w$ and that it is one of the letters in the phrase what time. In lines 12-15, Li is resaying the focal phrase in Taiwanese and in English. Shen and Li utter the phrase in Taiwanese. They hear it again in English (line 13) and then Li utters the phrase in English (line 14) surrounded by explanatory metatalk in Taiwanese, an attribution by Li of Tess proffering the information-seeking turn. Tess provides the focal phrase one more time (line 16) after which Shen makes a claim of understanding (line 17) in Taiwanese.

When there is no immediate claim of understanding by Li, Tess gives an elaborate embodied depiction of the activity that her query is referencing (line 18). This performative turn is complete with sound effects and then a visual cue for Li to respond to - the turn allocating gesture to Li at the end of Tess' turn (line 20). Li mimics Tess' pantomime and Li provides the second pair part in line 21 to Tess' information-seeking first pair part from line 5 which is confirmed in lines 23-25.

(1b) [10-14-04, 2002, 204, 46:47-47:09]

11 She: what is that ' $w$ ' is what time.

$12 \mathrm{Li}$ ((returns gaze to Shen)) what time \&^

she

13 Tes:

$14 \mathrm{Li}$ :

15

16 Tes:

li

17 She:

oh! she said what time.

18 Tes:

li

\&what ti:me do you get up.=so \&

19

\&gaze to Tess

\&gaze to Tess

\&gaze to board

^gaze to board

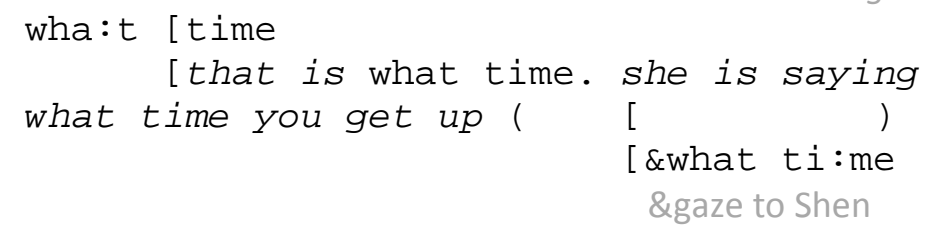

wha: $\mathrm{t}$ [time

[that is what time. she is saying what time you get up (

[\&what ti:me

\&gaze to Shen

+you're sleepi:ng,\& and then suddenly you go (.)

tes +pantomines sleeping

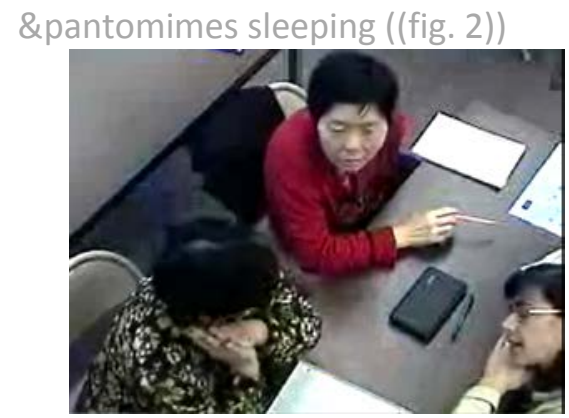

Figure $2 \mathrm{Li}$ and Tess pantomiming 'sleep'

$+\uparrow B R L I N N G::$ : and I have to wake up.

+lifts head suddenly as if waking

+what time

tes

$21 \mathrm{Li}:$

22 Tes:

seven(ty)

$23 \mathrm{Li}:$

seven?

24 Tes:

$\operatorname{mhm}(($ nods $))$

$25 \mathrm{Li}:$

okay. seven.

\&yeah.

li

\&nods

The excerpts in (1a) and (1b) show some of the micro interactional collaborative work in becoming competent (Schegloff 1989) to accomplish actions typical of classrooms. This work involves contextualized, embodied, and co-constructed language use. On a turn-by-turn scale, learning is embedded in the interaction among overlapping semiotic fields that become resources for the work of talk-in-interaction. In that interaction, Tess produced alternate fomulations, reducing a full information- 
seeking turn to key words and highlighted those words with sound stretches and prominence.

Simultaneously, Tess indexed a cultural artifact, a wristwatch, to illustrate the noun she highlighted (time) and made an embodied explanation of her turn that included sound effects and a pantomime of 'waking up', a performance which was partially repeated by Li.

Meanwhile, Li reformulated (translated) Tess' original first action into her L1. Li's peer, Shen, was an interlocutor for Li's talk in Taiwanese as well as the indexer of a visual resource when she pointed to a board with relevant print material. This interactional work indexed another semiotic field to provide evidence for interpreting Tess turn. Shen also provided an assertion, a claim of her own understanding in Taiwanese of what Tess was saying. One result of this is that Li provided the second pair part -'seven'- to the Tess' first pair part from line 5. Another way to characterize the result is that the competence to participate in the activity was a sequential process accomplished by Li, her peer Shen, and Tess.

Table 1 (below) is offered as an attempt to summarize Li's interaction in (1a) and (1b) without an overly-abstracted representation. The table outlines the series of actions and interactional practices used to accomplish those actions.

Table 1: Li's actions and practice pairs in excerpts $1 \mathrm{a}$ and $1 \mathrm{~b}$

\begin{tabular}{|c|c|c|}
\hline & $\begin{array}{l}\text { Description of the } \\
\text { Action or Practice }\end{array}$ & Line number \\
\hline Action & Response & \multirow[t]{4}{*}{7} \\
\hline Practice & $\begin{array}{l}\text { Translate part of } 1^{\text {st }} \\
\text { pair part into } L 1\end{array}$ & \\
\hline Action & $\begin{array}{l}\text { Candidate } \\
\text { understanding }\end{array}$ & \\
\hline Practice & $\begin{array}{l}\text { Translate part of } 1^{\text {st }} \\
\text { pair part into } L 1\end{array}$ & \\
\hline Action & $\begin{array}{l}\text { Confirmation } \\
\text { seeking }\end{array}$ & \multirow[t]{2}{*}{$7-8,14$} \\
\hline Practice & $\begin{array}{l}\text { State interpretation } \\
\text { of teacher directive } \\
\text { for peer using } L 1\end{array}$ & \\
\hline Action & Response & \multirow[t]{2}{*}{21} \\
\hline Practice & $\begin{array}{l}\text { Produce a single } \\
\text { lexical item } \\
\text { seven(ty) }\end{array}$ & \\
\hline Action & Response & \multirow[t]{2}{*}{23,25} \\
\hline Practice & $\begin{array}{l}\text { Produce a single non } \\
\text { lexical and lexical } \\
\text { items ( } \mathrm{mm} \mathrm{hm} \text {, } \\
\text { yeah) }\end{array}$ & \\
\hline
\end{tabular}

\section{Excerpt set 2: Li's ninth month in the classroom}

Although the micro-level examination has uncovered actions and practices in a learning setting, for learning, using a research design that systematically collected data from the same people over a period of time, we can compare actions practices of the same participant at a later time. This procedure has been used effectively by EMCA research to provide evidence of differences or change (Eskildsen 2015, Greer 2017, Ishida 2009, Theodorsdottir 2011, among others). Excerpt 2 shows the same focal participant in the same classroom in a similar activity in May of the following year. She is participating with a different peer, Sergio, in an activity in which students are given a question frame to use to ask one another questions about times of the day that they do certain activities. The question frame, that is, 
the language they are instructed to use to start the query to their peers is what time do you. On the white board and in the textbook on their desks, they have nine examples of activities they could ask about and use to complete the question frame. So, the interactional prompt here is identical to that from the October class in excerpts $1 \mathrm{a}$ and $1 \mathrm{~b}$.

What may be most notable in excerpt 2 is how Li's physical comportment differs from the October class. This is difficult to present on a transcript. But some evidence of it can be seen in lines 7 and 10 where Li presents herself as a reading participant in the classroom. As the teacher finishes the instructions for the task, Li shifts her posture setting up a new interactional frame, moving into a common work area with Sergio (line 7, figures 3 and 4). She then holds her hand over Sergio's workbook as she prepares to ask the first question of the task (line 10, figure 5). Li's launch of the task (line 11) begins just after the teacher finishes her instructions to the class (in line 8 , she assigns roles of questioner and answerer using the institutional roles of teacher and student). Li's task question is accompanied by three non verbal behaviors that gain Sergio's recipiency (touching his arm and gaze) as well as directing Sergio to relevant information for responding (pointing to the board).

(2a) [05-01-2003, 206, 1:09:03-1:09:20]

06 Te: no::w. practice together.

07 Li: ((shifts posture to common area with sergio figs 3 and 4$)$ )

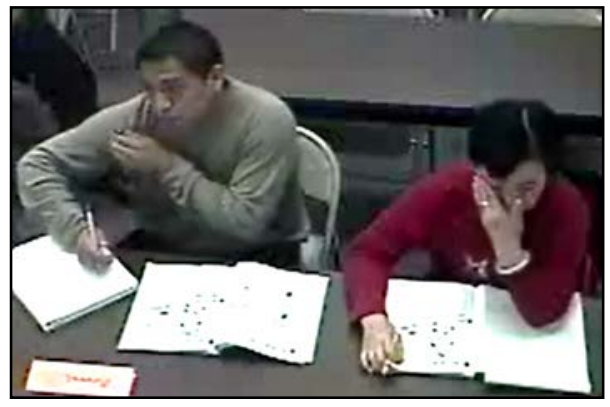

Figure 3: teacher reads instructions

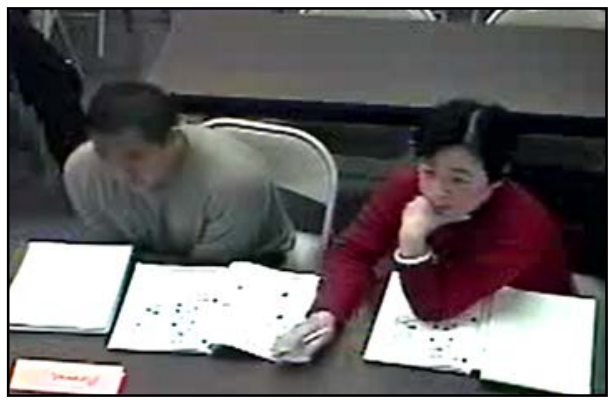

Figure 4: when teacher finishes instructions

08 Te: no::w. practice the questions. teacher, student. What

09 time do you. Practice together for about five minutes.

10 Li: ((hand over Sergio's workbook fig. 5 and looks at board))

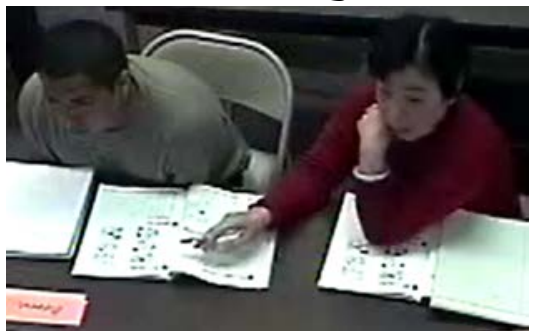

Figure 5: Li moves her hand over Sergio's book and looks to board

11

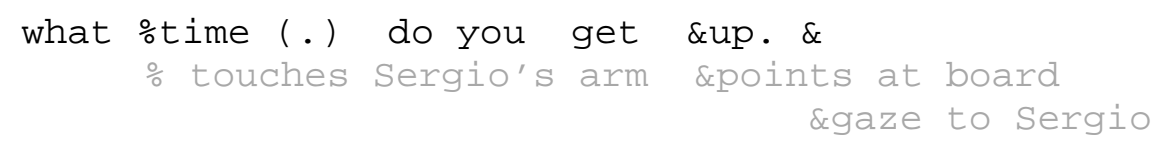

When Sergio does not respond immediately, in (2b), Li produces a laughter token in line 12 as well as a non verbal repair initiation, a gestural hint, pointing to something in Sergio's book. After this hint, Sergio provides the response to Li's first pair part in line 13 ('seven o'clock') which Li confirms in line 14 by repeating. She then asks the next question in the series (lines 14-15) which to which Sergio initiates repair (line 16). Li formulates the trouble source again and uses a deictic gesture to suggest where information can be found, and gives the numeral (line 19) that indexes the particular question she is articulating. I will not discuss the entire interaction here. However, what happens following (2b) is 
that Li finishes the series of questions to Sergio and then initiates a change in roles. She then responds to these same questions proffered by Sergio.

(2b) [05-01-2003, 206, 1:09:21-1:09:50]

12 Li: heh \&

li \&points to an image in Sergio's book

13 Se: s: : : : : :even (.) o [clock

14 Li: [\&se-seven o'clock. what time do you

li \&gaze at board

15 okuh.

16 Se: hm?

17 Li: what time do you okuh. \&okuh. eah. Li \&points at board

$18 \quad(2.0)$

19 Li: \&two.

20 Se: oh.

$21 \quad(1.0)$

22 Se: is (.) five.

We found these excerpts compelling in their illustration of the power of CA applied to longitudinal data. Using this method with these data, we are able to show contextualized interactional practices that are used to accomplish actions during a similar classroom language-learning activity by the same participant months apart. In excerpt 1 from October, the evidence suggests that Li is working out a proficiency for classroom interaction that experienced students already have. The instructor, Tess, oriented to Li as such a participant and Li's interaction displays inexperience with the activity being done by students at that time. The actions of Li include responding and seeking confirmation and the practices for those actions included use of the L1 and single lexical items in the L2 English. Although Li displayed to Shen (and to us via translation) that she understood Tess' directive what time do you get up, she had not experienced the purpose for the action that the information seeking turn by Tess was implementing. Li had not participated in a classroom before and so likely did not hear Tess' directive as an experienced student and, therefore, responded to Tess' directive only after doing the intermediary repair work. In those first excerpts, evidence for learning is available in the examination of the perseverance, the atthat-time orientation to moving through a sequence of talk-in-interaction using overlapping and resonant semiotic cues from a teacher and peer. This orientation leads to an outcome of a second pair part, a pedagogical goal, an 'answer' to a 'question'. This second pair part answer did not occur in the expected sequential slot (as the repair work that follows it shows). But over the course of 20 turns or so, intersubjectivity work was done to arrive at that second pair part to complete a sequence. The description of the intricate coordination of semiotic resources and the people using them to accomplish social action illustrates learning as a phenomenon that is action-oriented and embodied rather than the transfer and collection of symbolic linguistic representations.

The October and May excerpts seen consecutively (in table 2, below) illustrate a notable change in Li's comportment and practices for interaction and participation in a classroom task in May. In that second excerpt, Li interacts as an experienced student. At that second point in time, we want to say that $\mathrm{Li}$ 'exhibited' some practices for actions which are observable to the analyst and a teacher that she did not exhibit previously. She initiated the task (see Cekaite 2007 and Nguyen 2011 on initiations as indicators of proficiency), initiated repair, confirmed a peer's receipt token, and repaired her own talk. This is not an unexpected finding given the chronological perspective in the examination of longitudinal 
data. And such findings lend support for the purposes of formal education and, perhaps, the achievement of an individual language learner's goals.

Table 2 Li's actions and practice pairs in excerpts (1) and (2)

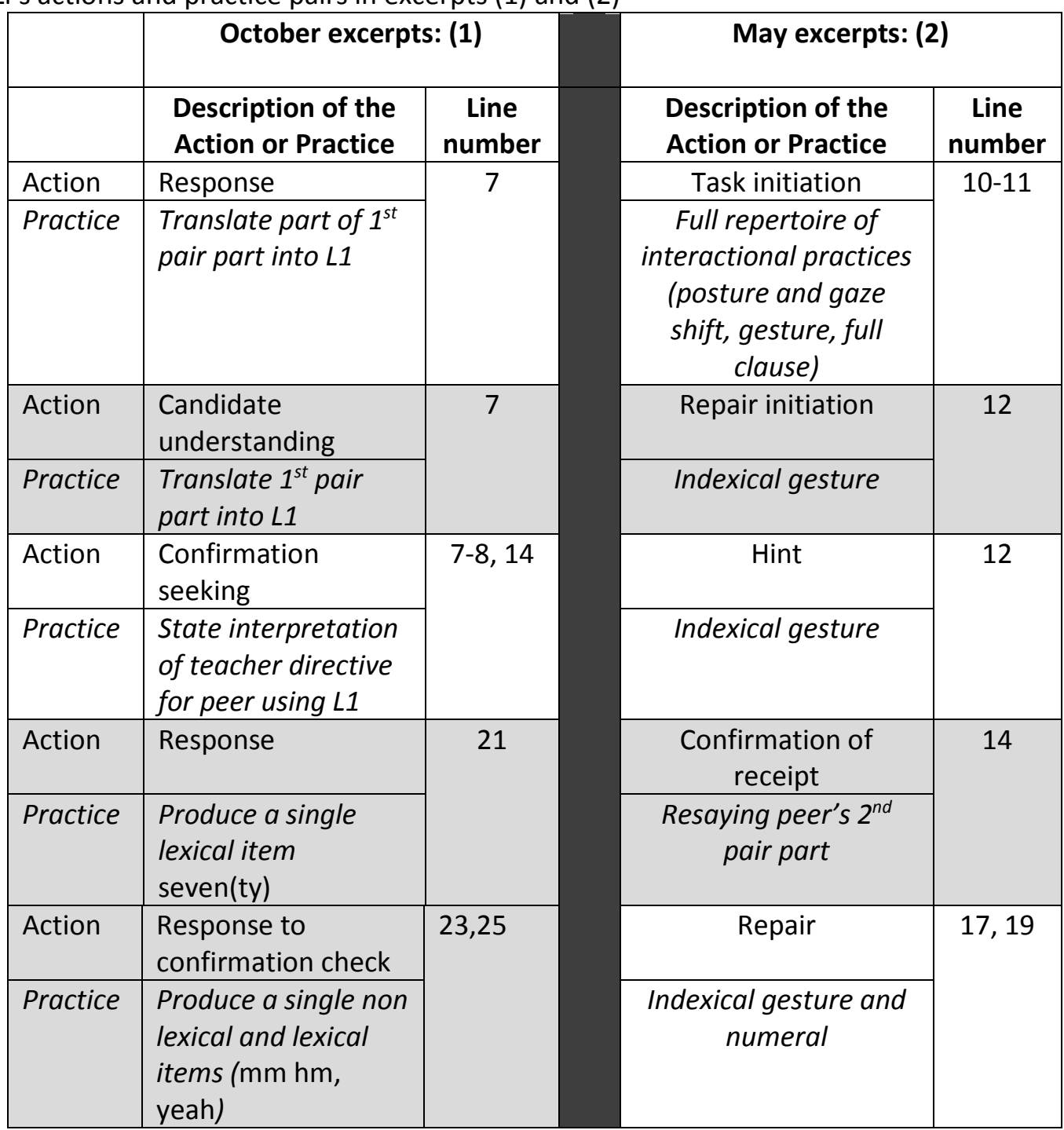

However, comparing this and other studies of Li (Hellermann 2017, Hellermann and Harris 2015) with other research on learners from this database (notably, Eskildsen's studies of 'Carlos' and 'Valerio', 2015), Li's case was compelling because institutional assessments of her language development (standardized tests) showed no change in her language proficiency in that same period of time. The excerpts showed, however, evidence of changes in contextualized talk-in-interaction for purposes of classroom work. The analysis of these excerpts does not focus morphosyntax, phonology, or the lexicon to trace evidence of change. Rather, what we see in the excerpts is that language practices are learned as the task for which the language practices are needed is being learned. The two are inseparable. In these excerpts, there is evidence of classroom practices being learned - the task (asking and answering questions of a stranger for purposes of language learning), the role of peer, classroom comportment. There is also evidence that a particular question formation habitus and interactional practices being learned. That sense of change in practices comes via our analysts' longitudinal lens, of seeing holistic differences and study of the micro-level details from which the whole is built. For Li's co-participants, 
especially in the second interaction, Sergio, the orientation to his and Li's language practices is an 'atthat-time' rather than longitudinal orientation. Li is initiating, repairing, hinting, and confirming at appropriate times for accomplishing a task. She is enacting know how. And that is oriented to by both participants and what allows the interaction to move forward.

\section{Conclusions}

\section{Representations}

Longitudinal data and a focus on language learners has been employed by EMCA researchers who investigate situated action and members' orientation to actions and practices (among the many studies, see Eskildsen and Wagner 2017, Pekarek Doehler and Berger 2015, Kim, forthcoming; Theodorsdottir 2017). These methods allow for increased construct validity for studies of language learning moving the focus of language acquisition research away from linguists' constructs and toward investigations of languaging (Becker 1988) for action. However, as the recent debate in Discourse Studies has highlighted (Macbeth, Wong, and Lynch 2016, Lynch and Macbeth 2016, Lynch and Wong 2016), EMCA studies themselves may be susceptible to an over-reliance on formal representations ( $\mathrm{K}+$, $\mathrm{K}$ - and the like) which may obscure the orientation to the nature of language as contextualized, embodied, talk-in-interaction.

For EMCA researchers of language learning, it is a challenge not to be distracted by linguistic forms, even in the transcripts of turns and sequences of turns, when we want to undertake actionoriented analyses of learning-as-process. Language as an underspecified cultural tool is a repertoire of approximations yet its encoding into written forms immediately suggests discrete, invariable structures. The metaphor of 'grammar-in-the-head' (mental linguistic representations) conveniently follows from the focus on written transcriptions of language. And for studies of language learning, the use of such a representation of language suggests that learners are more or less in possession of a fixed, abstract structural competence rather than as having more or less experience for language use to accomplish action in context.

Does the shorthand of grammatical abstractions $(S+V)$ serve practical purposes or do they simply serve the search for universals of acquisition and common pedagogies? Perhaps the formal abstractions are useful as written mediational tools to enable learners to analyze the language as analysts do. A language learner's repertoire for talk-in-interaction may be recognizable to coparticipants because of the contexts in which that repertoire is used, the work accomplished by it, and the common human-cultural heritage of the co-participants. An abstract representation of such a repertoire of practices (repair, for example) may then be a useful shortcut to formally teach one aspect of a language repertoire. Practicing applied research in this manner, we can avoid the positing of learning as intra-mental symbolic representation and manipulation, an electro-mechanical circuitry model. The shorthand like the tables used in the analysis above may be helpful to illustrate change in actions and practices but also highlights the difficulty of formally representing findings from EMCA studies of learning. As we know, we cannot easily distill what we uncover in EMCA to formal linguistic structures that can be modeled or measured in standardized assessments.

\section{Competencing among co-participants}

As discussed earlier, the EMCA conceptualizes competence as the accountable practices of members to do talk-in-interaction: interactional competence. The illustrations in this paper show CA methods describing actions and practices for those actions in the sequential structure of talk-ininteraction to give evidence for competence in process or competencing among language users. I use the progressive form (analogous to languaging) to emphasize an active, process orientation for competence and as a reminder that what has been labeled interactional competence does not exist in the abstract or out of context. That learning process is seen in members' displays of their accountability to one another in their situated inquiry with one another in settings oriented to as settings for learning. Evidence for this is also available in the displays of changing practices in talk for action in doing those 
displays in those settings. In the excerpts presented above, rather than determining what Li can take with her to use on a standardized language assessment, we are seeing the process of competent meaning making, the coordinated, embodied use of multiple resources for meaning making. The indexing of a peer's book is relevant in the way it was in excerpt 2 differently than it would be in another context. At that time, in that sequential slot, it is a repair initiation and hint. It is not English-language specific. However, it cannot be separated from the English language being done at that time. It is a display of Li's orientation to texts as semiotic/linguistic resources for accomplishing the work of a language learning task. It is part of the process of laying down the path that the learners take for their interaction.

There is no doubt that the development of language involves the complex convergence of semiotic, linguistic, historical, neuropsychological and other resources for language use, what MacWhinney (2005) called 'meshing', not all these aspects are visible using EMCA methods. However, this meshing involves both fortuitous, resonant, at-that-time experiences as well as repeated experiences over time. It is also what is involved in enactivist accounts of cognition. So, rather than how language resides in an individual, we want to focus on the connection of the relationship of the individual to the world (including co-participants in interaction) and the role of talk-in-interaction in that relationship. Microanalysis using EMCA allows us to begin to uncover "the power of culture and language to shape...the generative constitution of the intersubjective community" (Thompson, 2007, p. 409). This last claim advocates finding ways to show learning as the generative co-construction of intersubjectivity of person in-and-as environment and move beyond the assessment of individual's enaction and learning

Linguistic theory (whether it be usage-based, construction grammars, or integrational) and SLA are in need of the analytic methodology that EMCA provides. Transcriptions and analyses do not offer easy shortcuts or generalizations about what to learn but rather, they allow analysts to seriously engage with contextualized language use showing the intricacy and complexity of language learning. EMCA allows for the analysis of overlapping semiotic fields used in a collaborative way on the path of learning. From its phenomenological heritage, EMCA is the investigation of facticity rather than fact (MerleauPonty 1962), that is the process of sense-making. The method compels us to focus on how coparticipants co-construct talk and meaning. It is incompatible with a conceptualization of competence as how much or how much more one knows. Rather, the method is compatible with research that seeks to show "what is collectively known [and] who has access to it" (McDermott 2011, p. 412). This collective perspective suggests a next step for conceptualizing the situated competencing work (and concomitant development of the repertoire of approximations) of language learners will be to consider new representations for languaging. This might be in outlining contextually-embedded contingency grammars (Ford and Fox, 2015) that model the competencing work of co-participants. Such a conceptualization work would show the complexity and dynamism of language and help analysts and students to see the reasons languages are acquired in the manner they are. But then we should continue to wonder whether such grammar building is incompatible with the dynamism we have been illustrating.

\section{Acknowledgements:}

Some of the ideas for this paper were first presented at the ICOP conference in Neuchâtel, Switzerland, January 2017. I would like to thank Alan Zemel, Steve Thorne, Simona Pekarek Doehler, and Søren Eskildsen for contributing some of the ideas in this paper. They are not responsible for any of the infelicities or weak argumentation herein.

Barraja-Rohan, A.-M. 2015. "II told you'”: Storytelling development of a Japanese learning English as a second language." In Usage-based perspectives on second language learning, edited by T. Cadierno and S. Eskildsen, 271-304. Berlin: de Gruyter. 
Becker, A. L. 1984. "Toward a Post-Structuralist View of Language Learning: A Short Essay." Language Learning 33(2): 217-220.

Becker, A. L. 1988. Language in Particular: A Lecture. In Linguistics in Context: Connecting, Observing, and Understanding, edited by D. Tannen, 17-35. Norwood, N.J.: Ablex.

Brouwer, C. E., and J. Wagner. 2004. "Developmental Issues in Second Language Conversation." Journal of Applied Linguistics 1(1): 29-47.

Cekaite, A. 2007. "A Child's Development of Interactional Competence in a Swedish L2 Classroom." Modern Language Journal 91(1): 45-62.

Cole, M. 1996. Cultural Psychology: A Once and Future Discipline. Cambridge, MA: Belknap Press of Harvard University.

Cowley, S. J. 2009. "Distributed Language and Dynamics." Pragmatics \& Cognition 17(3): 495-508.

Eskildsen, S. W. 2012. "Negation Constructions at Work." Language Learning 62(2): 335-372.

Eskildsen, S. W. 2015. "What Counts as a Developmental Sequence? Exemplar-Based L2 Learning of English Questions." Language Learning 65(1): 33-62.

Eskildsen, S. W. and J. Wagner. 2017. "From Trouble in the Talk to New Resources: The Interplay of Bodily and Linguistic Resources in the Talk of a Novice Speaker of English as a Second Language." In Documenting Change Across Time: Longitudinal Studies of the Organization of Social Interaction, edited by In S. Pekarek Doehler, E. Gonzalez-Martinez, and J. Wagner, London: Palgrave.

Everett, D. L. 2016. Dark Matter of the Mind: The Culturally Articulated Unconscious. Chicago: The University of Chicago Press.

Filipi, A. 2015. "The Development of Recipient Design in Bilingual Child-Parent Interaction." Research on Language and Social Interaction 48(1): 100-119.

Ford, C. E. and B.A. Fox. 2015. "Ephemeral Grammar: At the Far End of Emergence." In Temporality in Interaction, edited by A. Deppermann and S. Günthner, 95-119. Amsterdam: John Benjamins.

Gallagher, S. (2017). Enactivist Interventions. Rethinking the Mind. Oxford: Oxford University Press.

Gallagher, S. and M. Allen. 2016. "Active Inference, Enactivism and the Hermeneutics of Social Cognition." Synthese 4(4): 1-22.

Greer, T. 2013. "Establishing a Pattern of Dual-Receptive Language Alternation: Insights from a Series of Successive Haircuts." Australian Journal of Communication 40(2): 47-62.

Hall, J. K. 1993. "The Role of Oral Practices in the Accomplishment of our Everyday Lives: The Sociocultural Dimension of Interaction with Implications for the Learning of Another Language." Applied Linguistics 14(2): 145-166.

Hall, J. K. 1995. “'Aw Man, Where You Goin'?': Classroom Interaction and the Development of L2 Interactional Competence." Issues in Applied Linguistics 6: 37-62.

Halliday, M. A. K. 1993. "Towards a Language-Based Theory of Learning." Linguistics and Education 5(2): 93-116.

Harris, R. 1981. The Language Myth. London: Duckworth.

Harris, R. 2009. Rationality and the Literate Mind. London: Routledge.

Harvey, M. 2015. "Content in Languaging: Why Radical Enactivism is Incompatible with Representational Theories of Language." Language Sciences 48(2): 90-129.

Hellermann, J. 2008. Social Actions for Classroom Language Learning. Clevedon, U.K.: Multilingual Matters.

Hellermann, J. 2011. “Members' Methods, Members' Competencies: Looking for Evidence of Language Learning in Longitudinal Investigations of Other-Initiated Repair." In L2 Interactional Competence and Development, edited by J. K. Hall, J. Hellermann, and S. Pekarek Doehler, 147172. Bristol, UK: Multilingual Matters.

Hellermann, J. and K. A. Harris. 2015. "Navigating the Language-Learning Classroom without Previous Schooling: A Case Study of Li." In Dialogue in Multilingual and Multimodal Communities, edited by D. Koike and C. Blyth, 49-77. Amsterdam: John Benjamins. 
Hellermann, J. 2017. "Talking about Reading: Changing Practices for a Literacy Event." In Longitudinal Studies in Conversation Analysis, edited by S. Pekarek Doehler, E. González-Martínez, and J. Wagner. Basinkstoke: Palgrave Macmillan.

Heritage, J. 1984. Garfinkel and Ethnomethodology. London: Polity Press.

Hopper, P. 1988. "Emergent grammar and the a priori grammar postulate." In Linguistics in Context:

Connecting, Observing, and Understanding, edited by D. Tannen, 117-134. Norwood, NJ: Ablex.

Hopper, P. J. 1998. "Emergent Grammar." In The New Psychology of Language: Cognitive and Functional Approaches, edited by M. Tomasello, 155-175. Hillsdale, NJ: Lawrence Erlbaum.

Husserl, E. 1980. Ideas Pertaining to a Pure Phenomenology and to a Phenomenological Philosophy. Book Two. Kluwer: Boston.

Hutchins, E. 1995. Cognition in the Wild. Cambridge, MA: MIT Press.

Hutto, D. D. and E. Myin. 2013. Radicalizing Enactivism: Basic Minds without Content. Cambridge, MA: MIT Press.

Ishida, M. 2009. "Development of Interactional Competence: Changes in the Use of ne in L2 Japanese During Study Abroad." In Talk-in-Interaction: Multilingual Perspectives, edited by G. Kasper \& H. Nguyen, 351-385. Honolulu, HI: National Foreign Language Resource Center.

Kasper, G. 1997. “'A' stand for Acquisition: A Response to Firth and Wagner." Modern Language Journal 81(4): 307-312.

Kasper, G. 2006. "Beyond Repair: Conversation Analysis as an Approach to SLA." AILA Review 19: 83-99.

Kasper, G. 2009. "Locating Cognition in Second Language Interaction and Learning: Inside the Skull or in Public View?" International Review for Research in Applied Linguistics 47(1): 11-36.

Kim, S. forthcoming. "'We Limit Ten under Twenty Centu Charge Okay?': Routinization of an Idiosyncratic Multi-word Expression." In Language in Action: CA studies of L2 Learning in the Wild, edited by J. Hellermann, S. Eskildsen, S. Pekarek Doehler, \& A. Piirainen-Marsh, Cham, Switzerland: Springer.

Koschmann, T. D. 2011. "Theorizing Practice." In Theories of Learning and Studies of Instructional Practice, edited by T. D. Koschmann, 3-17. New York: Springer.

Kramsch, C. 1986. "From Language Proficiency to Interactional Competence." Modern Language Journal 70(4): 372-366.

Lave, J. and E. Wenger. 1991. Situated Learning: Legitimate Peripheral Participation. Cambridge: Cambridge University Press.

Linell, P. 2005. The Written Language Bias in Linguistics: Its Nature, Origins and Transformations. London: Routledge.

Lynch, M. and D. Macbeth. 2016. "The Epistemics of Epistemics: An Introduction." Discourse Studies 18(5): 493-499.

Lynch, M. and J. Wong. 2016. "Reverting to a Hidden Interactional Order: Epistemics, Informationism, and Conversation Analysis." Discourse Studies 18(5): 526- 549.

Macbeth, D. 2011. "Understanding Understanding as an Instructional Matter." Journal of Pragmatics 43(2): 438-451.

Macbeth, D., J. Wong, and M. Lynch. 2016. The Story of 'Oh', Part 1: Indexing Structure, Animating Transcript." Discourse Studies 18(5): 550- 573.

MacWhinney, B. 2005. "The Emergence of Linguistic Form in Time." Connection Science 17(3-4): 191211.

Manzotti, R. 2016. "Experiences are Objects: Towards a Mind-Object Identity Theory." Rivista Internazionale Di Filosofia E Psicologia 7(1): 16-36.

Markee, N. 2000. Conversation Analysis. Mahwah, NJ: Lawrence Erlbaum Associates.

Markee, N. 2008. "Toward a Learning Behavior Tracking Methodology for CA-for-SLA." Applied Linguistics 29(3): 404-427.

McDermott, R. 2011. "Can we Afford Theories of Learning?" In Theories of Learning and Studies of Interactional Practice, edited by T. Koschmann, 403-413. Berlin: Springer. 
Merleau-Ponty, M. 1962. Phenomenology of Perception. New York: Routledge Classics.

Nguyen, H. T. 2011. "Achieving Recipient Design Longitudinally: Evidence from a Pharmacy Intern in Patient Consultations." In L2 Interactional Competence and Development, edited by J. K. Hall, J. Hellermann, and S. Pekarek Doehler, 173-205. Bristol, UK: Multilingual Matters.

Nguyen, H. T. 2012. Developing Interactional Competence. Basingstoke, Hampshire : Houndmills.

Ochs, E. 1988. Culture and Language Development: Language Acquisition and Language Socialization in a Samoan Village. Cambridge: Cambridge University Press.

Pekarek Doehler, S. 2010. "Conceptual Changes and Methodological Challenges: On Language and Learning from a Conversation Analytic Perspective on SLA." In Conceptualising Learning in Applied Linguistics, edited by P. Seedhouse, S. Walsh, and C. Jenks, 105-127. Basingstoke, UK: Palgrave Macmillan.

Pekarek Doehler, S. and E. Pochon-Berger. 2015. The Development of L2 Interactional Competence: Evidence from Turn-Taking Organization, Sequence Organization, Repair Organization and Preference Organization." In Usage-Based Perspectives on Second Language Learning, edited by T. Cadierno and S. Eskildsen, 233-267. Berlin: Mouton De Gruyter.

Pekarek Doehler, S. and E. Berger. 2016. "L2 Interactional Competence as Increased Ability for ContextSensitive Conduct: A Longitudinal Study of Story-Openings." Applied Linguistics.

Reder, S. 2005. "The 'Lab School'." Focus On Basics: Connecting Research and Practice 8: 1-7.

Schegloff, E. A. 1989. "Reflections on Language, Development, and the Interactional Character of Talk-inInteraction." In Interaction and Human Development, edited by M. H. Bornstein and J. S. Bruner, 139-153. Hillsdale, N.J.: Lawrence Erlbaum Associates.

Theodorsdottir, G. 2011. "Second Language Interaction for Business and Learning. In L2 Interactional Competence and Development, edited by J. K. Hall, J. Hellermann, and S. Pekarek Doehler, 5693. Clevedon, U.K.: Multilingual Matters.

Theodorsdottir, G. forthcoming. Development of Interactional Competence: Evidence from the Wild. In Language in Action: CA studies of L2 Learning in the Wild, edited by J. Hellermann, S. Eskildsen, S. Pekarek Doehler, \& A. Piirainen-Marsh, Cham, Switzerland: Springer.

Thompson, E. 2007. Mind in Life: Biology, Phenomenology, and the Sciences of Mind. Cambridge, MA: Harvard University Press.

van Lier, L. 2004. The Ecology and Semiotics of Language Learning. Boston: Kluwer.

Varela, F., E. Thompson, and E. Rosch. 1991. The Embodied Mind: Cognitive Science and Human Experience. Cambridge, MA: MIT Press.

Wagner, J. 2015. "Designing for Language Learning in the Wild: Creating Social Infrastructures for Second Language Learning." In Usage-Based Perspectives on Second Language Learning, edited by T. Cadierno and S. Eskildsen, 75-101. Berlin: De Gruyter.

Wertsch, J. V. and S. Kazak. 2011. "Saying More Than You Know in Instructional Settings. In Theories of Learning and Studies of Interactional Practice, edited by T. Koschmann, 153-166. New York: Springer.

Wootton, A. J. 1997. Interaction and the Development of Mind. Cambridge: Cambridge University Press. Young, R. F. 1999. "Sociolinguistic Approaches to SLA." Annual Review of Applied Linguistics,19: 105-32.

Zemel, A. and T. Koschmann. 2014. "Put your Fingers Right in Here': Learnability and Instructed Experience." Discourse Studies 16(2): 163-183. 